\title{
Cognitive Metaphors of Covid-19 Pandemic in Business News
}

\author{
Tetyana Kozlova ${ }^{1 *}$ \\ ${ }^{1}$ Zaporizhzhia National University, 69069 Zaporizhzhia, Ukraine
}

\begin{abstract}
The research considers the COVID-19 pandemic cognitive metaphors conveyed by means of the English language in business news. The interpretation of metaphor goes beyond its traditional understanding as a rhetorical device. The approach is consistent with a cognitive theory claiming that metaphor is a mental instrument to reflect the way we reason and imagine the world. The paper provides a brief theoretical framework of the research, discusses the concept, role and types of cognitive metaphor. It deals with particular cases of metaphoric representations of the pandemic selected from The Financial Times, an international daily with focus on business and economic affairs. The results of the study reveal a variety of lexical means to express the dynamic image of the pandemic that exhibits a gradual shift from the military metaphor to variant interpretations. The findings prove the pervasiveness of metaphor in business and mass media communication, its significance to understand difficult situations, efficiently communicate ideas and influence the audience.
\end{abstract}

\section{Introduction}

The outbreak and consequences of the COVID-19 pandemic will leave a deep mark in the consciousness of people all over the world. Because of its unexpectedness, rapid pace and global scale, the pandemic has forced significant changes into our lives. Under such circumstances, immediate response, and efficient prevention have become the greatest challenges faced by the world community. The enormity of the challenge issued by the dreaded pandemic is being discussed, explained, rationalized and interpreted in numerous publications relating medicine $[1,2]$ and other fields of science, politics, economics [3], education, culture [4, 5] to name but few. In addition to that, there exists a sizable academic literature discussing linguistic and communicative aspects of the pandemic crisis [6-8], addressing the ongoing events, tackling cognitive and emotional response to the unpredictable circumstances, and explaining how coronavirus outbreak communication is being handled by political, mass media and scientific communities.

\subsection{Background}

The studies with a focus on applied linguistics perspective were carried out to discover and explain new coinage related to Covid-19 situation, its influence on other languages and problems arising in the translation and coordination of terminology [9-11], generate taxonomies of terms with the help of corpus analysis and estimate word frequencies [12-14], collect and systematize massive Covid-19 related text data [15]. The findings shed light on the specificity of scientific and medical language which is significant in specialist and everyday discourse.
The findings revealed an unprecedented and rapid (within 3 months) growth in the frequency of pandemicrelated words (coronavirus, corona, COVID-19) compared to lexical items connected with recent political and social events (Brexit, impeachment) [13]. It was discovered that linguistic changes accelerated with the increase in names for social response and consequences (social distancing, self-isolation, etc.), economic impact (lockdown), and distant communication (zoom) [14].

The noticeable result of such linguistic change is the qualitative and quantitative expansion of the English vocabulary. The corona-related vocabulary amounts to approximately 500 items [11] which find equivalents in other languages. The quantitative change can be traced through linguistic creativity of speakers. According to Haddad \& Monterero-Martinez [9], a tremendous vocabulary expansion should be attributed to solving communication needs in specialist and everyday communication by filling lexical gaps. The data from various studies [9-15] indicated that most productive types of vocabulary development included metaphoric and metonymic transfers. Affixation, compounding, abbreviation, clipping and conversion prevailed over other word-building processes.

However, it is not only naming gaps that require to be filled. A more challenging task precedes creating naming labels. It is crucial for interlocutors is to cognize new aspects of reality, systematize new and old experience, evaluate things and events. The researches found that such concepts as disease, Covid-19, pandemic became prevalent in various types of discourse today. Having studied framing of Covid-19 in Twitter communication, Wicke \& Bolognesi [16] showed that the discourse around the pandemic made use of the "war", "monster", "storm", and "family" metaphors. The conclusion was made about "a metaphor menu"

\footnotetext{
* Corresponding author: ethstlab@yahoo.com
} 
facilitating the communication of various aspects connected with Covid-19.

Semino's [17] findings about the appropriateness of "fire" metaphors in communication about contagion and public health measures resulted from the analysis of news articles in English.

Other researchers analysed "war" metaphorisation of Covid-19 to discover the diverse arsenal of means of its manifestation in language and explain the diversity by socio-political individual variables speakers', such as political orientation [18], or by universal character of the war rhetoric [19-22].

Although much work has been done to date, more studies need to be conducted to ascertain whether different discourses and their various genres determine the type of metaphors they employ how they may vary.

\subsection{The purpose and methodology of research}

The purpose of this study is to investigate metaphoric representations of the Covid-19 pandemic in business news articles in English.

It is hypothesized that the universal metaphor "disaster is war" can manifest as a set of alternatives to communicate senses and ideas particularly significant for mass media interpretation of business affairs.

The material used in this research consisted of 125 metaphoric manifestations of the Covid-19 pandemic. The extracts were selected from The Financial Times (FT) articles placed online between February 2020 and January 2021.

The analysis of cognitive metaphors of the Covid-19 pandemic was based exclusively on the data collected from FT. This source was considered valid and credible for the following reasons. Firstly, FT is a respected international daily. Secondly, with its focus on business and economic affairs, it is generally regarded to be an authority in these subjects. Thirdly, in spite of the fact that it is primarily targeted at the readers interested in finance, FT is a newspaper with a wide coverage of topics attracting audience from various fields of life.

As to methods of material selection, it should be mentioned that modern "conceptual metaphor theory has no explicit methods for identifying conceptual metaphors" [23]. That is why a set of criteria was employed at the stage of empirical data selection. It was devised to ensure the presence of the lexical units Covid, Covid-19, coronavirus, corona, pandemic in the contexts, and the presence of some word/s the written utterance that could be taken figuratively (metaphorically), not literally. The choice also had to be made as to the appropriateness of the selected samples and the presence of cross-domain ties found in the expressions. To decrease the uncertainty and find systematicity in selected expressions, the following features were considered: similarity or polarity in meaning (struggle, fight; win, lose); shared semantic component/s and relatedness to the particular semantic field (fighter, hunter "someone who attacks); shared collocates (animal hunter, vaccine hunter, Covid hunter).
The collected samples covered a wide range of aspects of the pandemic including its outbreak and unfolding, the scale of spread, preventive measures, impact on business. The whole set was subjected to descriptive, contextual, semantic, and structural analysis employed in combination with conceptual analysis to make judgements about the mappings and the types of metaphors. Finally, the data were systematised to discover the source domains of metaphorisation and linguistic means of metaphoric manifestations.

\subsection{Paper structure}

The paper is structured as follows. Section 2 gives a brief account of the theoretical basis for the research and systematizes the key principles of the theory of cognitive metaphor, its types and significance in communication.

Section 3 presents the analysis of metaphoric interpretations of the Covid-19 pandemic disaster and means of their manifestation in business news. It also discusses variant metaphoric conceptualisations of Covid-19 pandemic elaborated by speakers from different but related to the military domain spheres of knowledge. Furthermore, this section deals with the business news rhetoric and expressivity of means employed to communicate about the pandemic.

\section{Theoretical basis for the research}

\subsection{Traditional and innovative definitions of metaphor}

There is an agreement among traditional and cognitive linguists on the importance and pervasiveness of metaphor. The history of the theory of metaphor has its roots in the distant past.

The earliest accounts about metaphor are found in the works of Aristotle and other ancient philosophers who treated metaphor as a rhetorical figure, an element of speech decoration and the demonstration of eloquence skill. Such approach was determined by the social environment in ancient Greece and established democracy when all political innovations, rise to power, endurance of laws and political achievements could be, though not secured, but assisted by argumentation, pervasiveness, impressiveness of communication of necessary ideas. Metaphors played a significant role in adding suggestive power to rhetoricians' and critics' elegant speeches, "the grand, also called "lofty," ... florid speech that impresses with sound" [24]. Since then, the influential potential of metaphors has never been questioned.

In later studies, metaphor was defined in terms of traditional linguistics as a path of meaning development that occurs due to the associative transfer on the basis of similarity between two entities in question. Thus, linguistic metaphor is associating between two referents which resemble each other. From that classical point of view, metaphors are based on various types of similarity (shape, position, colour, etc.) and discussed as similies, 
personifications, spatial images, transfers of sensation and the like.

Considered as a product of logical ties, metaphor is treated as a naming technique with characterising function.

Lakoff and Johnson [25] paid attention to the mental/conceptual spaces and how they operate with knowledge domains. Fauconnier and Turner [26, 27] discovered How they can preserve structures and make permanent correspondences, or how they can blend them. In contemporary linguistics, metaphor is tackled from a cognitive point of view. It is acknowledged that metaphor is an instrument of thinking, reasoning about the world.

The interplay occurs between the source domain of and the target domain of metaphor. The former contains some knowledge or experience with which new knowledge is identified. The latter is the sphere to which metaphor is applied. The structural correspondences between the source and target domains are defined as mappings (or metaphor maps).

The theory of metaphor was enriched by Kövecses who expressed doubts on whether literal language existed at all, argued that contextual metaphors were also conceptual ones [28], developed the theory of the scope of metaphor [29]. He discovered that metaphors can be derived from several domains in order to interpret an abstract concept.

These and other contributions into the theory of cognitive/conceptual metaphor added to the understanding of the variety of metaphors.

\subsection{Types and significance of cognitive metaphors}

Cognitive metaphors break into several types depending on what sources and mechanisms they employ to represent a more complex idea: conduit metaphors that deal with viewing communication, ontological metaphors and personification that the most basic as they allow to interpret abstract ideas, events, etc. as entities and objects, structural metaphors that structure one concept in terms of another, orientational metaphors that allow to ground our experience of the wold with the spatial experience.

The role of cognitive metaphors is crucial in our life. They enable appropriate orientation in the environment, systematisation of our experience, provide contiguity of knowledge and cultural values. Despite their representative nature, they are not deprived of descriptive potential. They help us to depict the world, build up images, compare and recognise various properties of things around us. They are also of importance for the creative and cognitive development of humans.

As to communication, cognitive metaphors carry out a set of functions. They link and harmonise individual cognitive processes with those of the social group. They become persuasive performatives responsible for implicit inclination, involvement, invitation, etc.
Metaphors are invaluable suggestive tools shaping social behaviour and thought.

Their psychological role is no less significant. With the help of analogy carried by metaphors, speakers are less vulnerable to cognitive disorders, better cope with stressful circumstances, avoid communicative failure. In sum, metaphors are mediators between the world and the human, between the society and an individual. For mass media communication, metaphoric effects are vital in the sense that metaphorical patterns become models of thought and behaviour of the recipients of information.

\section{Results and discussion}

The epidemic disaster has influenced the way we think and speak about the world, society and various spheres of life, particularly business and economy, environment, health issues. Moreover, our perception and reasoning of the crisis shapes the way we communicate about it. Most appropriate and common way of interpreting the pandemics is in terms of the war. The discourse of business news makes use of both the common and military parlance around the current disaster.

\subsection{Military metaphor: the epidemic as a common foe}

The world is seen as a war zone where people are fighting with the disease: "Europe battles to contain surge in Covid-19 cases" (FT, 29 July 2020), "...countries fight Covid-19 resurgence" (FT, 25 Dec 2020), "We need to aggressively stop the spread now" (FT, 5 Dec 2020), "hospitals and intensive care units are struggling to cope." (FT, 21 March 21 2020). In business news, the current events relating to the coronavirus outbreak are represented in terms of an armed conflict with the help of the words denoting a fight, an armed conflict, pressure or the use of force (battle, beat, buckle, combat, conquer, defeat, fight, struggle). For example, "War on superbugs must follow defeat of Covid-19" (FT, 20 Dec 2020), “...the reality of Britain's "wartime economy" in the era of coronavirus" (FT, 27 March 2020).

Experienced difficulties and great efforts made to win the battle and overcome the pandemic are interpreted as shooting from a gun - " '... bullet' to beat Covid-19" (FT, 29 July 2020), while a record of the virus spread is seen as following the target - "coronavirus tracked" (FT, 25 Dec 2020). In metaphoric representations, warnings of danger are portrayed as alarms given by a loud noise or flashing light: "US states sound alarm on Covid-19 hospitaliazations" (FT, 5 Dec 2020).

Reporting on coronavirus-related deaths has also added to the image of a military disaster with enormous loss of life: "Death toll surges" (FT, 22 March 2020), "... worst day for mortalities in escalating European outbreak" (ibid.).

Preventive measures are described as actions demanded by law: order mandatory testing, impose measures, urge mask use and other expressions are 
frequent in the texts of daily business news. Both in cases of armed conflicts and epidemic disasters, restrictive measures are taken against regional instability as well as protection of people and property. Among other things, pandemic restrictive defence includes Covid-19 border control, lockdown, isolation, distancing: "World on lockdown: West closes borders and orders isolation" (FT, 18 March 2000), “... western economies took drastic measures to limit public movement on Monday, closing borders, shutting down retailers and ordering citizens to stay in their homes in an urgent effort to arrest the spreading coronavirus pandemic" (ibid.)

The key conceptual feature "common", that is "the same enemy in a lot of places or for a lot of people" is explicitly expressed by adjectives meaning "relating to the whole world" (global, international, world-wide, etc.), nouns denoting "the act of working together" (cooperation, collaboration, etc.). For example, "Global cooperation is needed to beat the virus" (FT, 29 Jan 2021). Grammatical means such as the marker of the plural of nouns $(-s)$, the plural pronouns (we, us, they, them) and determiners (our, their) are also employed to communicate the idea of "common foe": "Governments must restore these freedoms when the virus is eventually beaten” (FT, 29 Jan 2021), “... we'll be shooting to get to a year's immunity" (FT, 23 Sept 2020), "To our relief and surprise, the number of cases have started to come down..." (FT, 29 Jan 2021). While the use of noun plurals and adjectives with cooperative meanings is unambiguous, the plural pronoun we/us can vary according to the context. It can be either semantically inclusive (i. e. including the addresser(s)/speaker(s) and the addressee) or exclusive (i. e. excluding the addresser(s)/speaker(s) but including other people as the addressees): "We won't remember much of what we did in the pandemic" (FT, 14 Aug 2020). However, news reporters seem to favour explicit methods and make a clear reference by adding other words (we all) or employing generic uses of personal pronouns to refer to people in general. For instance, "...what we all feel about the high number of ... the global pandemic and the rapidly evolving economic crisis" (FT, 4 Jan 2021), "The next pandemic: where is it coming from and how do we stop it? As deforestation and climate change increase spread of new diseases, meet the virus-hunters trying to prevent the next Covid-19" (FT, 29 Oct 2020). In contrast, the concepts of loneliness and isolation during the pandemic are successfully verbalized by the nominative and accusative personal pronouns $(I, m e)$ : “ $I$ live alone, I work alone, I'm hundreds ..." (FT, 20 Nov 2020), "Loneliness and me. Millions of us were living with this curse before the pandemic. How can we break it?" (ibid.).

Overall, the military metaphor has appeared to be a remarkably efficient tool in reasoning and reporting about the pandemic. The prior knowledge of war as a conflict between particular actors which is characterized by violence, social disruption, and economic destruction is linked to new experience. Inasmuch as cognizers bridge what they already know (an armed conflict) to a new entity (the Covid-19 pandemic), they create a new cognitive space that results from framing the target domain (the pandemic) in terms of the source domain (the war). Hence, if the Covid-19 pandemic is interpreted with the help of the military metaphor, then it will produce an image of "the war against the common aggressor". However, there are diverse applications of the "common foe" description in business news reports.

\subsection{Variant conceptualizations of the pandemic as a foe}

Variant conceptualizations of the Covid-19 pandemic appeal to different but related cognitive domains. They differ in the sphere of knowledge that is prioritized by business news reporters who target to create eloquent images of the pandemic: knowledge and experience in military affairs, hunting, games, killing a monster, and dealing with liquid are not alike. Despite that fact, these domains enable speakers to establish associative links with the image of "common foe" and provide corresponding mappings between the source domains and the target domain of the metaphor. In other words, variant conceptualizations of the Covid-19 pandemic have resulted from one-to many ties between the target domain and the source domains.

The relationship between the actors of the situation (the pandemic versus humanity, society, business, economy, etc.) is alternatively considered as competition in which one party becomes victimized ("victim of the pandemic" (FT, 29 Jan 2021)). Let us look into specific cases:

In the hunting metaphor, the actors of the pandemic situation come up as the hunter (scientists, investors) and the game/wild beast (the virus): "Hunting for new viruses has become more difficult during an actual pandemic, but it has never been more important" (FT, 29 Oct 2020), "on the hunt for a cure" (FT, 14 May 2020), "Investors' hunt for coronavirus rebound stocks" (FT, 11 Feb 2020), "Investors hunt for alternative data to track coronavirus shock..." (FT, 18 Feb 2020).

Being metaphorically considered as game players, the actors of the pandemic situation are conceptualized as the competing participants: "Vaccine makers prepare for game of Covid cat and mouse. Manufacturers and regulators need to be ready if shots prove less effective..." (FT, 10 Jan 21), "Asia plays a long game on Covid vaccine rollout" (FT, 15 Dec 2020), “... attempts to play down Covid-19" (FT, 29 Oct 2020).

The virus disaster has reshaped the way we talk about society, politics and economy dividing businesses and agencies into winners and losers: “... winners and losers in the Covid economy" (FT, 10 Oct 2020), "Three ways the banks will be winners from Covid recovery" (FT, 16 Nov 2020), "This year, Covid-19 has brought some of the most powerful countries in the world to their knees" (FT, 29 Oct 2020), "Covid-19 unmasks weakness of English public health agency" (FT, July 22, 2020).

Another way to communicate the struggle against the pandemic is the metaphor "a fight with a monster": "Coronavirus turns the City [London business center] 
into a ghost town" (FT, 27 July 2020). "'Silver bullet' to beat Covid-19 unlikely" (FT, 29 July 2020) seems to be a transparent allusion to the stories about werewolves and vampires fired to death with silver bullets by vampirehunters. This conceptualization is a very interesting instance of the cognitive frame development. It is based on the mapping between the vampire lore and the contemporary knowledge about the evil of pandemic. Furthermore, it provides a convincing evidence to the existence of conceptual ties among different domains of knowledge and experience. By this the consistency of mapping is achieved within the frame representation of the active agent as a hunter / fighter (cf. animal hunter, vaccine hunter and Covid hunter as semantically close expressions implying "someone who is trying to find and get the desired/stated thing"). The explanation that can be suggested for such a metaphor of the pandemic is that cognitive metaphors are not single, independent tools of our cognition but complex mental images embracing sets of associated featured.

\subsection{The expressive language of metaphoric manifestations}

The findings about the linguistic means of metaphoric manifestations showed that reporters employed typical for the news discourse expressivity. As is clear, expressive vocabulary and structures enable addressers to encode their emotions and evaluations of the current situation. Expressivity provides efficiency in expressing the addressers' intentions as well as their individuality. In addition to that, expressivity of speech allows to achieve loftiness in communication. What follows is the systematization and examples of the expressive means found in the selected contexts:

- words with inherent expressivity and mostly negative meanings (dreadful "causing shock and suffering", monstrous "very cruel", vicious "showing an intention to hurt badly" as in "We can defeat this invisible and vicious adversary [coronavirus] - but only with global leadership" (FT, 25 March 2020)), which may be intensified in the context (extraordinary "very strange, unusual" as in extraordinary crisis; curse "speak angrily" as in live with this curse (FT, 21 Nov 2020));

- words with inherent expressivity and intensive meanings (to surge "to increase suddenly and greatly", to hit "to move one's hand with force; to produce a negative, unpleasant effect", to thrive "to grow and become successful"; boom "a sudden increase in something" as in "Europe fears as coronavirus surge threatens to overwhelm hospitals" (FT, 23 Oct 2020), "Nations look into why coronavirus hits ethnic minorities so hard" (FT, 29 Apr 2020));

- colourful phraseological units (get your act together "organize and deal with something effectively", bleak future "without anything to make one feel happy or hopeful, be on one's knees "be weak" as in "Covid brings China's high-growth rental industry to its knees" (FT, 18 Nov 2020)) and their occasional modifications (for example, the idiom to have the stomach for "to be brave or determined to do something dangerous or unpleasant" was transformed into to lose the stomach "to become exhausted because of doing something difficult" as in "America is losing the stomach to fight Covid-19" (FT, 11 Jun 2020));

- names of imaginary entities (ghost "the spirit of dead, transparent image", to haunt "(of a ghost) to appear in a place repeatedly, cause anxiety or suffering" as in "If Covid-19 is not beaten in Africa, it will return to haunt us all" (FT, 25 March 2020);

- phrasal verbs (to lose out "to not have an advantage as other people have" as in "The kids aren't alright. How generation Covid is losing out" (FT, 17 Nov 2020); to bounce back "to return to a usual state after having a problem" as in "... if the virus is not defeated in Africa, it will only bounce back to the rest of the world" (FT, 25 March 2020)).

The following quote is an example of how neutral words get involved into utterances with expressive vocabulary and acquire intensification to communicate about the pandemic disaster: "Gap between financial markets and global economy yawns wider ... We have a monster mash-up of the Great Depression in size, the crash of ... effects of measures" (FT, 24 Apr 2020). Owing to the proximity of distance between the expressive (yawn wider, monster, mash-up, crash) and neutral vocabulary, the latter become emotionally charge. Thus, "effects of measures" should be interpreted as "ineffectual and unable to produce good results under the circumstances".

In the following passage, the involvement of the intensive verb surge provides expressivity for the whole utterance, suggesting complete destruction of most powerful (major) economic systems: "Pandemic triggers surge in business start-ups across major economies" (FT, 29 Dec 2020).

\section{Conclusions}

The results of the research proved the importance of cognitive metaphors in different spheres and genres of communication. The study of cognitive metaphors of the Covid-19 epidemic in FT daily provided evidence to the fact that the target domain of metaphors in question is actual for the coverage of various topics, directly or indirectly related to the themes of financing and business. It can be explained by the drastic and global scale influence of the epidemic on the economic sphere.

The prevalence of military metaphor can be explained by the universal nature of the concept "disaster is war". However, in internationally oriented business communication, reporters suggest the idea of the pandemic as a "common foe", implying the necessity for cooperation in coping with the crises stimulated by the disaster. Although this scenario demonstrates alternative metaphoric representations (Covid is an animal to be hunted, a competitor/player to be defeated, a monster to be destroyed), they are attracted by the central idea of the common enemy.

The linguistic means involved to manifest metaphors demonstrate expressivity typical of the news discourse. 
Business news articles are an interesting and influential genre of mass media communication. It is an awesome challenge to extend the research of cognitive metaphors in business news reported by means of various languages in a variety of cultural settings. Further research into cognitive metaphors of the Covid19 pandemic calls for historical and comparative study broadening the perspective on the similarities and differences in the experience, behaviour and practices of coping with a disaster and communicating about it.

\section{References}

1. A. M. Baig, M. Chronic COVID Syndrome: Need for an appropriate medical terminology for Long-COVID and COVID Long-Haulers. Jrn. of Med. Virol. (2020). doi:10.1002/jmv.26624

2. D. Ricks, 100 Questions \& Answers About Coronaviruses (Jones \& Bartlett Learning, Burlington, 2021)

3. D. Seedhouse, The Case for Democracy in the COVID-19 Pandemic (SAGE Publications, London, 2020)

4. A. Bradshaw, J. Hietanen, The Dictionary of Coronavirus Culture (Repeater Books, London, 2020)

5. J. S. Spence, Covid-19, Exposition and Poetry on Coronavirus: An Education in Literary Notes Uplifting (Clever Fox Publishing, Chennai, 2020)

6. D. Lilleker, I.A. Coman, M. Gregor, E. Novelli (eds.), Political Communication and COVID19: Governance and Rhetoric in Times of Crisis (Routledge, New York, 2021)

7. H. D. O'Hair, M. J. O'Hair, Communicating Science in Times of Crisis: Coronavirus (Wiley-Blackwell, New York, 2021)

8. S. Molthagen-Schnöring, Communicating Science in Covid Times: Why communication with "the public" is not the goal of science communication. Eleph. In the Lab (2020). doi:10.5281/zenodo.3956336

9. H. Haddad, S. Monterero-Martinez. COVID-19: a metaphor-based neologism and its translation into Arabic. JCOM 19(05), (2020). doi:10.22323/2.19050201

10. L.-Ch. Chen, K.-H. Chang, H.-Y. Chung A Novel Statistic-Based Corpus Machine Processing Approach to Refine a Big Textual Data: An ESP Case of COVID-19 News Reports. Appl. Sci. 10 (5505), (2020). doi:10.3390/app10165505

11. H. Ma, L. Shen, H. Sun, Z. Xu, L. Xou, S. Wu, A. Fang, J. Li, Q. Qian. COVID Term: A Bilingual Terminology for COVID-19. Res. Sq. (2020). doi: 10.21203/rs.3.rs-30923/v1 (in press)

12. T. Stewart, July 2020 update: scientific terminology of Covid-19. (OED, 2020), https://public.oed.com/blog/july-2020-update- scientific-terminology-of-covid-19/. Accessed 14 Dec 2020

13. Corpus analysis of the language of Covid-19 (OED, 2020), https://public.oed.com/blog/corpus-analysisof-the-language-of-covid-19/. Accessed 10 Dec 2020

14. Using corpora to track the language of Covid-19: update 2 (OED, 2020),

https://public.oed.com/blog/using-corpora-to-trackthe-language-of-covid-19-update-2/. Accessed 10 Dec 2020

15. COVID-19 Open Research Dataset (CORD-19). Version 2020-05-02 (Allen Institute for AI, 2020), https://pages.semanticscholar.org/coronavirusresearch. Accessed 10 May 2020

16. Ph. Wicke, M. M. Bolognesi, Framing COVID-19: How we conceptualize and discuss the pandemic on Twitter. PLoS ONE 15(9). doi:10.1371/journal.pone.024prevalent0010

17. E. Semino, "Not Soldiers but Fire-fighters" Metaphors and Covid-19. Health Commun. 36(I), (2021). doi:10.1080/10410236.2020.1844989

18. M. Silvera-Roig, Lecture: Covid-19 and Conceptual Metaphor Theory: Disease is War (Complutense University of Madrid, 2020), https://youtu.be/jyiWRpd_3qU. Accessed 28 Sept 2020

19. D. Fernández-Pedemonte, F. Casillo, A. I. JorgeArtigau, Communicating COVID-19: Metaphors We "Survive" By. Tripod. 47(2), 145-159 (2020)

20. B. Nerlich. Metaphors in the time of coronavirus, https://blogs.nottingham.ac.uk/makingsciencepublic/ 2020/03/17/metaphors-in-the-time-of-coronavirus/. Accessed 14 Dec 2020

21. A. Sirait, K. Seva, Th. R. Lingga, Conceptualizing Corona Virus Metaphor in Media Headlines: a Cognitive Semantic Approach. Eng. Jrnl. Lit. Utama 5(1) (2020).

doi:https://doi.org/10.33197/ejlutama.vol5.iss1.2020 .477

22. C. Oswick, D. Grant, R.Oswick, Categories, Crossroads, Control, Connectedness, Continuity, and Change: A Metaphorical Exploration of COVID-19. JABS, 56(3), 284

23. R. W. Gibbs, Jr. and M. Perlam, in Cognitive Linguistics: Current Applications and Future Perspectives, ed. by G. Kristiansen, M. Achard, R. Dirven, F. J. R. de Mendoza Ibáñez (Mouton de Gruyter, Berlin, 2006), p. 215

24. K. Cmiel, Democratic Eloquence: The Fight Over Popular Speech in Nineteenth century America, University of California Press, Berkley, 1991), p. 21

25. G. Lakoff, M. Johnson, Metaphors We Live By (The University of Chicago Press, Chicago \& London, 1980), p. 3-147

26. G. Fauconnier, M. Turner, The Way We Think: Conceptual Blending and the Mind's Hidden 
Complexities (Perseus Group, New York, 2002), pp. 17-59, 279-298

27. G. Fauconnier, Ten Lectures on Cognitive

Construction of Meaning (BRILL, Leiden, 2018), pp. 94-117

28. Z. Kövecses, in Extended Conceptual Metaphor Theory (Cambridge University Press, Cambridge, 2020), pp. 93-116

29. Z. Kövecses, Metaphor and Metonymy at the Crossroads Metaphor (de Gruyter Mouton, Berlin, 2003), pp.79-92 